\title{
Type 2 diabetes mellitus in children and adolescent: an Indonesian perspective
}

\author{
Aman Bhakti Pulungan, MD, \\ PhD, FAAP', \\ Ireska Tsaniya Afifa, MD², \\ Diadra Annisa, MD² \\ ${ }^{1}$ Endocrinology Division, Child \\ Health Department, Faculty of \\ Medicine University of Indonesia \\ - Cipto Mangunkusumo Hospital, \\ Jakarta, ${ }^{2}$ Faculty of Medicine, \\ University of Indonesia, Jakarta, \\ Indonesia.
}

The prevalence of type 2 diabetes mellitus (T2DM) in children and adolescents has increased globally over the past 2 decades. Metabolic syndrome, including obesity and overweight at a young age, increases the occurrence of T2DM. Studies in Indonesia have found that obese children and adolescents are more likely to have insulin resistance, a risk factor for T2DM. There are no data on the current incidence of T2DM in youth in Indonesia, but there has been a significant rise in the prevalence of overweight in adolescents. The diagnosis of T2DM in youth is similar to that in adults, with special consideration of when to test asymptomatic children. Management of T2DM in Indonesia follows the recommendations of the Indonesian Pediatric Society, which include lifestyle modifications, such as improving dietary habits and exercise, as well as appropriate medications. Metformin is the drug of choice for young T2DM patients; if marked hyperglycemia is present, basal insulin is given with metformin. Monitoring of T2DM is generally done through selfmonitoring of blood glucose and glycosylated hemoglobin.

Keywords: Type 2 diabetes mellitus, Insulin resistance, Child, Adolescent, Indonesia

\section{Introduction}

Type 2 diabetes mellitus (T2DM) is an emerging noncommunicable disease (NCD) in children and adolescents. The vast problem of NCD was addressed in the Sustainable Development Goals, which was to reduce mortality caused by NCD by one third in 2030 .

T2DM is a complex metabolic disorder that may arise due to the influence of several factors, including genetic, social, environmental and behavioral factors. The balance of glucose metabolism in our body is influenced by insulin action, glucose production by liver and glucose intake by cells. All abnormalities that resulted in disturbed glucose transport and insulin resistance (IR) will cause hyperglycemia, which can lead to manifestations of diabetes. ${ }^{1)}$

In T2DM, an imbalance between insulin sensitivity and secretion leads to IR and $\beta$ cell damage. The result of several cross-sectional and longitudinal studies of high-risk population suggested that even in prediabetic conditions when blood glucose levels are still normal, hyperinsulinaemia and IR may be present.

The incidence of T2DM over the last 2 decades has increased significantly. In Japan, the incidence of T2DM is increased twofold from 7.3 to 13.9 per 100,000 in primary schoolaged children. ${ }^{2}$ In Thailand, T2DM in children and adolescents increased from 5\% during 1986-1995 to $17.9 \%$ in 1996-1999. ${ }^{3)}$ Moelyo et al. ${ }^{4)}$ found 38 children and adolescents with T2DM from the Indonesian National Registry in 2009-2012. Due to poor registration and awareness in healthcare workers, the real incidence of T2DM in youth in Indonesia is believed to be higher. According to the National Basic Health Survey (NBHS) of Indonesia in 2013, the proportion of DM in people aged more than 15 years was $6.9 \%$.

T2DM in younger people often occurs in the second decade of life with an average age https://orcid.org/0000-0003-48954105 
of 13.5 years. It is often associated with peak of puberty and physiological IR in younger age. The SEARCH for Diabetes in Youth Population study found that the highest proportion of T2DM was among 10-19 years individuals. Male to female ratio varies greatly from 1:4 to 1:6 in Native Americans and 1:1 in Libyans and Asians.

\section{Childhood obesity and diabetes mellitus}

Childhood obesity is an emerging problem worldwide. Globally, World Health Organization (WHO) reported an increase of overweight and obese children, from 32 million in 1990 to 41 million in 2016. The majority of these children live in developing countries, mainly in Asia and Africa. The rate of increase was estimated to be $30 \%$ higher than in developed countries. In adolescents, the rate is even higher, reaching to over 340 million in 2016 globally.

According to the 2013 NBHS, prevalence of overweight and obesity among Indonesian children aged 5 to 12 years are $10.8 \%$ and $8.8 \%$ respectively. This prevalence dropped as the children mature into adolescence, where the prevalence of overweight and obesity are $8.3 \%$ and $2.5 \%$ among adolescents aged 13 to 15 years. During late teenage years of 16 to 18 years old, the prevalence further dropped to $5.7 \%$ for overweight and $1.6 \%$ for obesity. Compared to the 2007 NBHS data, there is a significant rise the in prevalence of overweight in adolescents, from $1.4 \%$ in 2007 to $7.3 \%$ in $2013 .{ }^{1)}$ Long-term obesity leads to the occurrence of metabolic syndrome, such as T2DM, hypertension, dyslipidemia, coronary artery disease, polycystic ovarian syndrome, and nonalcoholic steatotic hepatitis.

\section{IR and metabolic syndrome}

Metabolic syndrome is a collection of symptoms consisting of hypertriglyceridemia, central obesity due to accumulation of visceral fat tissue, hyperinsulinemia and hyperuricemia. There are several variation in the definition of the metabolic syndrome in children, e.g., definition by the WHO, the National Cholesterol Education Program's Adult Treatment Panel III, and the European Group for the Study of IR. While their definitions differ, all organizations agreed that essential components of the metabolic syndrome include glucose intolerance, obesity, hypertension, and dyslipidemia. The current criteria for metabolic syndrome are based on the 2007 International Diabetes Federation Consensus Group, which is divided by age group. ${ }^{9)}$
IR is the underlying pathophysiology of metabolic syndrome. ${ }^{10)}$ A study by Hendarto ${ }^{11)}$ in Jakarta, Indonesia showed that $31 \%-75 \%$ of superobese children aged $<10$ years are insulin resistant. Sensitivity to insulin is influenced by ethnicity, puberty status, gender, birth weight, blood pressure, high-density lipoprotein (HDL), family history of obesity and T2DM, dyslipidemia, presence of acanthosis nigricans and lifestyle.

Several theories have connected the link between the incidence of obesity, metabolic syndrome, and IR. Obesity can result in IR and endothelial dysfunction through a series of reciprocal metabolism of fat, hormones, and adipocytokines. Various methods are used to determine the incidence of IR in obese children with metabolic syndrome: by measuring fasting insulin levels, using the homeostasis model assessment-IR (HOMA-IR) method, hyperglycemic-euglycemic clamp, or by measuring the levels of C-peptide to measure IR.

Childhood obesity may continue into adulthood, which may increase the risk of developing metabolic syndrome, which then leads to long-term complications, such as T2DM and coronary heart disease.

Pulungan et al. ${ }^{12)}$ reported the prevalence of IR in obese adolescents in Jakarta, Indonesia is 38\%, using the HOMAIR measurement method. The study revealed that IR in obese adolescents was highest among girls, individuals with a family history of obesity, and individuals with symptoms of acanthosis nigricans. Less than $10 \%$ of obese adolescents had impaired fasting glucose, but no obese teenagers with T2DM were present. Prevalence of metabolic syndrome was 19.6\%, with the majority being female adolescents, individuals with a family history of obesity, central obesity, dyslipidemia and hypertension. The presence of IR increases the risk of impaired fasting glucose by 5.7 times. Another study by Tirtamulia et al. ${ }^{13)}$ reported that prevalence of IR among obese adolescents in Manado, Indonesia is $62 \%$ and $82 \%$ of them were positive for acanthosis nigricans. This study found a weak correlation between IR and acanthosis nigricans.

\section{Risk factors for T2DM in children and adolescents}

Family history of obesity, T2DM or glucose intolerance, dyslipidemia, and gender are several major risk factors for developing IR in children and adolescents. IR can be suspected by taking patient history, physical examination and laboratory investigation. Table 1 shows the risk factors for IR in children

Table 1. Risk factors for insulin resistance in children and adolescents ${ }^{14-27)}$

\begin{tabular}{lc}
\hline Medical history & Physical examination \\
\hline Female sex & Obesity (visceral fat accumulation) \\
Low birth weight and early infant weight gain & Acanthosis Nigricans \\
Medications (glucocorticoids, antiretrovirals, antipsychotic drugs) & Increased blood pressure \\
Polycystic ovarian syndrome & - \\
Family history of type 2 diabetes mellitus & - \\
\hline
\end{tabular}


and adolescents.

\section{Obesity}

Obesity is a major risk factor for T2DM in children and adults. Both IR and defective insulin secretion appear very prematurely in obese patients and would eventually lead toward diabetes. Up to $50 \%$ of obese children and adolescents have IR. Primary obesity alone can cause hyperinsulinemia and IR as a result of increased fatty deposits. When fat deposit builds up, glucose intolerance due to IR will be evident. Visceral fat accumulation may lead to greater IR compared to subcutaneous fat accumulation. ${ }^{14)}$ Possible molecular basis of T2DM, related to obesity, include defects of glucokinase enzyme, ${ }^{15)}$ GLUT2 transporter protein enzyme glycogen synthase, ${ }^{16)}$ RAD (Ras Associated with Diabetes) insulin receptor, apolipoprotein III, and possibly epigenetic changes via an enzyme called DNA methyltransferase $3 \mathrm{a}^{17)}$

\section{Gender}

Juarez-Lopez et al. ${ }^{18)}$ found that among obese children and adolescents age 11-13 in Mexico, hyperinsulinemia were observed in $71 \%$ of girls but only in $45 \%$ of boys $(P<0.001)$. IR was also more prevalent in girls than boys (63\% vs. $43 \%$, $P<0.001)$.

\section{Birth weight}

Birth weight is also a major risk factor because low birth weight increases the risk of IR, obesity, cardiovascular diseases, and T2DM, especially if accompanied by rapid weight gain during early life. ${ }^{19,20)}$

\section{Medications}

Drugs affecting appetite, glucose and insulin or fat metabolism, such as glucocorticoids, ${ }^{21)}$ antiretroviral ${ }^{22)}$ and antipsychotic drugs $^{23)}$ can also influence insulin sensitivity.

\section{Acanthosis nigricans}

The presence of acanthosis nigricans or polycystic ovarian syndrome is associated with IR and obesity. Acanthosis is a skin manifestation characterized by the presence of skin hyperpigmentation that can usually be found in the area of skin folds of the neck, hands, and other body parts, while the polycystic ovarian syndrome is a disorder of the reproductive system characterized by hyperandrogenemia and chronic anovulation. Kobaissi et al. ${ }^{24)}$ studied the association between achantosis nigricans and IR, and found that in overweight children who had risk of developing T2DM, achantosis nigricans was an independent risk factor for the occurrence of IR.

\section{Dyslipidemia}

Increased fat deposit, including visceral fat, has been shown to be associated with low insulin sensitivity. The Cardiovascular Risk in Young Finns Study ${ }^{25)}$ found that high fasting insulin in children will lead to metabolic syndrome. Cruz et al. ${ }^{26)}$ examined the relationship between insulin sensitivity or IR with metabolic syndrome in overweight Hispanic adolescents with a family history of T2DM. In this study, it was revealed that insulin sensitivity positively correlates to serum HDL $(P<0.01)$ and negatively correlates to serum triglycerides $(P<0.001)$ and systolic and diastolic blood pressure.

\section{Blood pressure}

Ferrannini et al. ${ }^{27)}$ discovered that each 10-unit increase in IR will increase systolic blood pressure by $1.7 \mathrm{mmHg}$ and increase diastolic blood pressure by $2.3 \mathrm{mmHg}$.

\section{Diagnosis of type 2 diabetes mellitus}

Diagnosis of T2DM is made by a series of history taking, physical examination, laboratory workup and other relevant diagnostics. In general, T2DM patients are usually diagnosed at the age of 10 or in mid to late puberty. Common findings are obesity, family history of T2DM and acanthosis nigricans. In some children, classic manifestations such as polyuria, polydipsia, nocturia, enuresis, and weight loss may be present, while others can be asymptomatic. Chronic hyperglycemia may impair growth and renders the child to be more susceptible to infections. In asymptomatic or mild T2DM, diagnosis is made by screening or medical check up to detect glucosuria or hyperglycemia. Children with T2DM may exhibit glucosuria without ketonuria, polydipsia, no or mild polyuria and weight loss. Around $74 \%-100 \%$ of children with T2DM also have a family history of T2DM, indicating a strong genetic link in this disease. $^{28)}$

Table 2 shows the recommendations for diagnosis of

\section{Table 2. Criteria for the diagnosis of diabetes mellitus}

I. Classic symptoms of diabetes or hyperglycemic crisis, with plasma glucose concentration $\geq 11.1 \mathrm{mmol} / \mathrm{L}(\geq 200 \mathrm{mg} / \mathrm{dL}$ ) or

II. Fasting plasma glucose $\geq 7.0 \mathrm{mmol} / \mathrm{L}(\geq 126 \mathrm{mg} / \mathrm{dL})$ or

III. Two-hour postload glucose $\geq 11.1 \mathrm{mmol} / \mathrm{L}$ ( $\geq 200 \mathrm{mg} / \mathrm{dL}$ ) during an $\mathrm{OGTT}^{\dagger}$ or

IV. $\mathrm{HbA}_{1 \mathrm{c}}>6.5 \%$ (48 $\mathrm{mmol} / \mathrm{L}$ ) - if tested in a certified laboratorium. $\mathrm{HbA}_{1 \mathrm{c}}$ as a sole marker to diagnose $\mathrm{DM}$ is still controversial.

OGTT, oral glucose tolerance test; $\mathrm{HbA}_{1 c}$ glycosylated hemoglobin; DM, diabetes mellitus.

*Fasting is defined as no caloric intake for at least 8 hours. ${ }^{\dagger}$ OGTT is performed with a glucose load of $75 \mathrm{~g}$ anhydrous glucose dissolved in water or $1.75 \mathrm{~g} / \mathrm{kg}$ of body weight to a maximum of $75 \mathrm{~g}$.

Adapted from American Diabetes Association, Indonesian Pediatric Society, 2018. ${ }^{32)}$ 
T2DM from the Indonesian Pediatric Society (adapted from the guidelines of the International Society for Pediatric and Adolescent Diabetes [ISPAD, 2014], American Diabetes Association [ADA], and American Academy of Pediatrics) ${ }^{29-31)}$

- Diagnostic criteria for diabetes are based on laboratory measurement of plasma glucose concentrations; a marked elevation of the blood glucose level confirms diabetes, as well as the presence or absence of symptoms. Criteria for the diagnosis of diabetes mellitus can be seen in Table 2 .

- Measurement of diabetes autoantibody should be performed in all children with clinical diagnosis of T2DM, since there is an increase of islet cells autoimmunity cases.

- Measurement of diabetes autoantibody should be done in all overweight and obese children aged 13 and above presenting with clinical manifestation of type 1 diabetes, such as weight loss and ketosis or diabetic ketoacidosis (DKA), as these cases might be positive for T2DM.

- C-peptide level should be measured in overweight and obese children aged 13 and over with poor glucose control using oral hypoglycemic drugs, or those who are advised to switch medication to insulin, or for classifying type of diabetes.

- Because IR is associated to cardiovascular risk, severe complications are seen more in patients with type 2 rather than type 1 diabetes.

Screening, or testing for T2DM is not recommended for all children. Only children presenting with risk factors for diabetes are routinely tested, since the disease is associated with high morbidity and long-term complications. Children at risk with T2DM based on the Indonesian Pediatric Society guidelines are: $^{33)}$

- Children/adolescents with obesity,

- Family history of T2DM or cardiovascular diseases, and

- Signs of IR: acanthosis nigricans, dyslipidemia, hypertension, polycystic ovarian syndrome.

Currently, there is no recommendation of screening initiation, frequency, and the preferred test for T2DM screening in Indonesia. ${ }^{33)} \mathrm{ADA}$ recommends initiation at age 10 or onset of puberty, minimum every three years if results are normal, or more frequently if BMI is increased. The preferred test is glycosylated hemoglobin $\left(\mathrm{HbA}_{1 \mathrm{c}}\right)^{28)}$

\section{Management of type 2 diabetes mellitus}

As a multifactorial disease, managing diabetes in children may be challenging. The Indonesian Pediatric Society recommends the management of T2DM that includes lifestyle modification, oral hypoglycemic drugs (metformin), and insulin therapy. ${ }^{32}$ The goals of T2DM management by the Indonesian Pediatric Society can be seen in Table 3 .

To change their habits and modify their lifestyle, children are advised to increase their physical activity, lose weight, and eat selectively. Recommendation for dietary habit in children with diabetes is based on healthy diet to meet their daily needs.
Selection of food types should be adapted to their culture, ethnicity, and psychosocial needs. Since children usually are very bonded to their family, it is also important to engage their family to adopt the healthy eating lifestyle.

\section{Dietary recommendation}

A large portion of children and adolescents with T2DM are either overweight or obese. Therefore, their nutritional management should be focused in patient and family education and intervention of lifestyle to prevent weight gain and to revert their weight back to ideal weight, according to growth chart and to ensure growth to the maximum potential. Dietary modifications recommended in Indonesia include avoiding drinks with added sugar, consuming of five or more servings of fruits and vegetables, limiting consumption of instant or processed food, controlling the amount of food per serving, reducing times eating out, and substituting high glycemic index carbohydrate to low glycemic index carbohydrate. ${ }^{33)}$

\section{Physical activity}

Aside from correcting their eating habits, physical activity also plays a major role in managing children and adolescents with T2DM. The Indonesian Pediatric Society T2DM guidelines adapted physical activity recommendations from WHO, in which it is advised that every child should be active and encouraged to engage in at least 60 minutes of moderate-tovigorous activity every day and muscle- and bone-strengthening activities for at least 3 days every week. Screen time should be limited to less than 2 hours per day. ${ }^{33,34)}$

\section{Medication}

Prescription of oral hypoglycemic drugs is tailored for each children, according to their clinical manifestation. Based on the Indonesian Pediatric Society recommendation (2018), patients with moderate T2DM (fasting plasma glucose of 126 to 200 $\mathrm{mg} / \mathrm{dL}, \mathrm{HbA}_{1 \mathrm{C}}<9 \%$ ) could be managed by lifestyle modification combined with oral hypoglycemic drugs. ${ }^{32)}$ These drugs are designed to lower the IR threshold, promote insulin secretion, or limit postprandial glucose absorption. At the initial treatment and during therapy, it is important to examine for renal

Table 3. Goals of T2DM management (Indonesian Pediatric Society, 2015) ${ }^{33)}$

\begin{tabular}{l} 
1. Patient education to promote self-diabetes care \\
2. Normal blood glucose level \\
3. Weight loss (in obese T2DM patients) \\
4. Limiting carbohydrate and calorie intake \\
5. Promoting physical activities \\
6. Controlling comorbidities, including hypertension, dyslipidemia, \\
nephropathy, sleep disorders and other conditions related to T2DM \\
\hline T2DM, type 2 diabetes mellitus.
\end{tabular}


function and serum creatinine routinely, since there are risks for developing renal insufficiency as the disease progress.

The preferred and only U.S. Food and Drug Administrationapproved oral hypoglycemic agent for children with good renal function $\left(>30 \mathrm{~mL} / \mathrm{min} / 1.73 \mathrm{~m}^{2}\right)$ is metformin. ${ }^{29)}$ Metformin belongs to the biguanid group that works by reducing the hepatic glucose production while increasing glucose uptake in peripheral tissues. This drug also boosts insulin sensitivity, improves blood glucose levels without causing weight gain and lowers the $\mathrm{HbA}_{1 \mathrm{C}}$ level without the risk of hypoglycemia. Furthermore, triglycerides and low-density lipoprotein cholesterol tends to fall during metformin consumption.

Indonesian Pediatric Society recommends the initial metformin dose of $250 \mathrm{mg} /$ day for 3-4 days, titrated to $500 \mathrm{mg} /$ day divided into to 2 doses, and gradually increased for 3-4 weeks with the maximum dose $2,000 \mathrm{mg} /$ day. Common side effects for metformin are diarrhea, nausea, dyspepsia, bloating, and abdominal pain. These side effects should disappear as the medication continues. Contraindication for oral hypoglycemic drugs are metabolic acidosis and recurrent DKA. ${ }^{32}$

Children and youth with marked hyperglycemia (blood glucose $\geq 250 \mathrm{mg} / \mathrm{dL}, \mathrm{HbA}_{1 \mathrm{C}}>9 \%$ ) without ketoacidosis who are symptomatic at diagnosis should be treated with basal insulin while metformin is initiated and titrated to achieve the targeted $\mathrm{HbA}_{1 \mathrm{c}}{ }^{32)}$ The recommended initial dose of insulin in Indonesia is $0.25-0.5 \mathrm{IU} / \mathrm{kg} /$ day, and can be titrated until the targeted blood glucose level is reached. Change of regimens from the combination of insulin and metformin into metformin alone can be done in 2-6 weeks. The insulin dose is decreased gradually by $30 \%-50 \%$ while the metformin dose is increased. ${ }^{33)}$ Children and adolescents with T2DM often have cardiovascular complications; hence, hypertension and dyslipidemia should be treated according to age-specific guidelines.

\section{Monitoring of blood glucose}

The best glycemic control should be performed by selfmonitoring of blood glucose (SMBG) because hypoglycemic and hyperglycemic conditions can be monitored real time to ensure optimalization of therapy. ADA recommends SMBG to be done at different times, such as: at bedtime, during the night and after overnight fast to detect and prevent nocturnal hypoglycemia and hyperglycemia, also to optimize basal insulin; during the day, prior to meals and 2 hours after a meal to help determine meal insulin doses; in association with vigorous exercise to observe the child's blood sugar profile; to confirm hypoglycemia and to monitor recovery; and during intercurrent illness to prevent hyperglycemic crisis. The frequency of SMBG depends on the availability of the examination device, regimen of insulin given, the child's capability of detecting hypoglycemia, and the cost of SMBG testing. ${ }^{28,35)}$ The Indonesian Pediatric Society recommends SMBG more than three times a day for patients using basal-bolus regiments or insulin pump. Meanwhile, patients using only basal insulin or oral medications can monitor blood glucose less frequently. ${ }^{33)}$

Measurement of $\mathrm{HbA}_{1 \mathrm{c}}$ provides the profile of mean blood glucose in the past 2 to 3 months, weighted towards the most recent four weeks, and is used as a gold standard for long-term metabolic control. ADA and ISPAD recommend a target of $<7.5 \%$ (58 $\mathrm{mmol} / \mathrm{mol})$ in all patients younger than 18 years, ${ }^{28.33)}$ while the Indonesian Pediatric Society recommends a lower target, $<6.5 \%{ }^{33)}$ When hypoglyemic unawareness occurs, severe hypoglycemia is more common, hence the $\mathrm{HbA}_{1 \mathrm{c}}$ targets must be increased. Frequency of $\mathrm{HbA}_{1 \mathrm{c}}$ measurement depends on local resources, the recommendation in Indonesia is at least every 3 months, similar to the ISPAD. ${ }^{33,36)}$

\section{Psychological and neurocognitive problems in diabetic youth}

Depression, anxiety, psychological distress, and eating disorders occur more frequently in youth with diabetes especially with chronic poor metabolic control. Thus, it is important to include mental health specialists (psychologists, social workers, and psychiatrists) in the interdisciplinary diabetes care team. ${ }^{29,37)}$

Several studies on neurocognitive function in children with T2DM shows that poor glycemic control may increase the risk of learning difficulties and weakens information processing, primarily in children who have early onset diabetes and a history of severe hypoglycemia. ${ }^{29)}$

\section{Family and care-provider support in T2DM management}

The ability of the patient's family to implement the education and medication given is the key to effective diabetes treatment. The diabetes care team must involve the family in all aspects of diabetes management, including to evaluate factors (psychosocial, emotional) affecting the treatment of T2DM. In school-aged children, communication with school or day care providers is also important to ensure optimal diabetes management, patient safety, and to maximize academic achievements. $^{29,38)}$

\section{Conclusion}

Awareness should be raised in young individuals who are clinically at high risk of T2DM, and therefore should be screened regularly. Interventions should aim to accommodate healthy lifestyle, including limitation of food intake and engagement of physical activities. Clinicians must make sure that T2DM patients get optimal tailored-medication and that family and peers are involved in diabetes management. All stakeholders must engage in these efforts, including the government, professional organizations, and community in general. 


\section{Conflict of interest}

No potential conflict of interest relevant to this article was reported.

\section{References}

1. Arslanian S. Type 2 diabetes in children: clinical aspects and risk factors. Horm Res 2002;57 Suppl 1:19-28.

2. Kitagawa T, Owada M, Urakami T, Yamauchi K. Increased incidence of non-insulin dependent diabetes mellitus among Japanese schoolchildren correlates with an increased intake of animal protein and fat. Clin Pediatr (Phila) 1998;37:111-5.

3. Likitmaskul S, Kiattisathavee P, Chaichanwatanakul K, Punnakanta L, Angsusingha K, Tuchinda C. Increasing prevalence of type 2 diabetes mellitus in Thai children and adolescents associated with increasing prevalence of obesity. J Pediatr Endocrinol Metab 2003;16:71-7.

4. Moelyo AG, Himawan IW, Pateda V, Fadil R. Indonesian national registry of children with type 2 diabetes mellitus. Int J Pediatr Endocrinol 2013;2013(1 Suppl):P8.

5. Indonesian Health Ministry. National basic health survey. Jakarta: Indonesian Health Ministry, 2013.

6. Pettitt DJ, Talton J, Dabelea D, Divers J, Imperatore G, Lawrence JM, et al. Prevalence of diabetes in U.S. youth in 2009: the SEARCH for diabetes in youth study. Diabetes Care 2014;37:402-8.

7. World Health Organization. Childhood overweight and obesity [Internet]. Geneva (Switzerland): World Health Organization; 2016 [cited 2018 Jul 12]. Available from: http://www.who.int/dietphysicalactivity/childhood/en/.

8. Sinha R, Fisch G, Teague B, Tamborlane WV, Banyas B, Allen K, et al. Prevalence of impaired glucose tolerance among children and adolescents with marked obesity. N Engl J Med 2002;346:802-10.

9. Alberti G, Zimmet P, Shaw J, Bloomgarden Z, Kaufman F, Silink M, et al. Type 2 diabetes in the young: the evolving epidemic: the international diabetes federation consensus workshop. Diabetes Care 2004;27:1798-811.

10. Caceres M, Teran CG, Rodriguez S, Medina M. Prevalence of insulin resistance and its association with metabolic syndrome criteria among Bolivian children and adolescents with obesity. BMC Pediatr 2008;8:31.

11. Hendarto A. Telaah peran leptin, adiponektin, tumor necrosis-, C reactive protein, asupan karbohidrat dan lemak terhadap resistensi insulin pada anak lelaki superobes usia 5-9 tahun. Disertasi. Jakarta: Fakultas Kedokteran Program Doktor Ilmu Kedokteran Universitas Indonesia, 2009.

12. Pulungan AB, Puspitadewi A, Sekartini R. Prevalence of insulin resistance in obese adolescents. Paediatr Indones 2013;53;167-72.

13. Tirtamulia KS, Umboh A, Warous SM, Pateda V, Regina F. Achantosis nigricans and insulin resistance in obese children. Paediatr Indones 2010;50:274-7.
14. Hardy OT, Czech MP, Corvera S. What causes the insulin resistance underlying obesity? Curr Opin Endocrinol Diabetes Obes 2012;19:81-7.

15. Agius L. Targeting hepatic glucokinase in type 2 diabetes: weighing the benefits and risks. Diabetes 2009;58:18-20.

16. Ait-Omar A, Monteiro-Sepulveda M, Poitou C, Le Gall M, Cotillard A, Gilet J, et al. GLUT2 accumulation in enterocyte apical and intracellular membranes: a study in morbidly obese human subjects and ob/ob and high fat-fed mice. Diabetes 2011;60:2598-607.

17. Choi CHJ, Cohen P. How does obesity lead to insulin resistance? Elife 2017 Dec 14;6. pii: e33298.

18. Juárez-López C, Klünder-Klünder M, Medina-Bravo P, Madrigal-Azcárate A, Mass-Díaz E, Flores-Huerta S. Insulin resistance and its association with the components of the metabolic syndrome among obese children and adolescents. BMC Public Health 2010;10:318.

19. Vaag A. Low birth weight and early weight gain in the metabolic syndrome: consequences for infant nutrition. Int J Gynaecol Obstet 2009;104 Suppl 1:S32-4.

20. Fabricius-Bjerre S, Jensen RB, Færch K, Larsen T, Mølgaard $\mathrm{C}$, Michaelsen KF, et al. Impact of birth weight and early infant weight gain on insulin resistance and associated cardiovascular risk factors in adolescence. PLoS One 2011;6:e20595.

21. Zhou PZ, Zhu YM, Zou GH, Sun YX, Xiu XL, Huang $X$, et al. Relationship between glucocorticoids and insulin resistance in healthy individuals. Med Sci Monit 2016;22:1887-94.

22. Feeney ER, Mallon PW. Insulin resistance in treated HIV infection. Best Pract Res Clin Endocrinol Metab 2011;25:443-58.

23. Deng C. Effects of antipsychotic medications on appetite, weight, and insulin resistance. Endocrinol Metab Clin North Am 2013;42:545-63.

24. Kobaissi HA, Weigensberg MJ, Ball GD, Cruz ML, Shaibi GQ, Goran MI. Relation between acanthosis nigricans and insulin sensitivity in overweight Hispanic children at risk for type 2 diabetes. Diabetes Care 2004;27:1412-6.

25. Raitakari OT, Juonala M, Rönnemaa T, Keltikangas-Järvinen L, Räsänen L, Pietikäinen M, et al. Cohort profile: the cardiovascular risk in Young Finns Study. Int J Epidemiol 2008;37:1220-6.

26. Cruz ML, Weigensberg MJ, Huang TT, Ball G, Shaibi GQ, Goran MI. The metabolic syndrome in overweight Hispanic youth and the role of insulin sensitivity. J Clin Endocrinol Metab 2004;89:108-13.

27. Ferrannini E, Natali A, Capaldo B, Lehtovirta M, Jacob S, Yki-Järvinen H. Insulin resistance, hyperinsulinemia, and blood pressure: role of age and obesity. European Group for the Study of Insulin Resistance (EGIR). Hypertension 1997;30:1144-9.

28. American Diabetes Association. Standards of medical care in diabetes - 2018. Diabetes Care 2018;41(Suppl 1):S1-159.

29. American Diabetes Association. Children and adolescents: standards of medical care in diabetes 2018. Diabetes Care 
2018;41(Suppl 1):S126-36.

30. Craig ME, Jefferies C, Dabelea D, Balde N, Seth A, Donaghue KC, et al. ISPAD clinical practice consensus guidelines 2014. Definition, epidemiology, and classification of diabetes in children and adolescents. Pediatr Diabetes 2014;15 Suppl 20:4-17.

31. Copeland KC, Silverstein J, Moore KR, Prazar GE, Raymer T, Shiffman RN, et al. Management of newly diagnosed type 2 Diabetes Mellitus (T2DM) in children and adolescents. Pediatrics 2013;131:364-82.

32. Endocrinology Working Group, Indonesian Pediatric Society. Diagnosis and treatment of type 2 diabetes mellitus. Jakarta: Indonesian Pediatric Society, 2018.

33. Indonesian Pediatric Society. National consensus on management of type II DM in children and adolescents. Jakarta: Indonesian Pediatric Society, 2015.

34. Robertson K, Riddell MC, Guinhouya BC, Adolfsson P, Hanas R; International Society for Pediatric and Adolescent Diabetes. ISPAD clinical practice consensus guidelines
2014. Exercise in children and adolescents with diabetes. Pediatr Diabetes 2014;15 Suppl 20:203-23.

35. Rewers MJ, Pillay K, de Beaufort C, Craig ME, Hanas $\mathrm{R}$, Acerini CL, et al. ISPAD clinical practice consensus guidelines 2014. Assessment and monitoring of glycemic control in children and adolescents with diabetes. Pediatr Diabetes 2014;15 Suppl 20:102-14.

36. Hanas R, John WG; International HbAlc Consensus Committee. 2013 Update on the worldwide standardization of the hemoglobin Alc measurement. Pediatr Diabetes 2014;15:e1-2.

37. Delamater AM, de Wit M, McDarby V, Malik J, Acerini CL. Psychological care of children and adolescents with type 1 diabetes. Pediatric Diabetes 2014;15(20 Suppl):232-44.

38. Lange K, Swift P, Pańkowska E, Danne T; International Society for Pediatric and Adolescent Diabetes. ISPAD clinical practice consensus guidelines 2014. Diabetes education in children and adolescents. Pediatr Diabetes 2014;15 Suppl 20:77-85. 